\title{
Oculoskeletal Myopathy with Abnormal Mitochondria
}

\author{
V. Bril, N. B. Rewcastle, J. Humphrey
}

\begin{abstract}
A clinical, electrophysiological and pathological review of 14 patients having oculoskeletal myopathy with abnormal mitochondria was undertaken. These patients present with ophthalmoplegia, and mild skeletal muscle weakness. The clinical course is slowly progressive. Electromyographic examination shows myopathic changes. Serum enzymes are normal. The diagnosis is confirmed by skeletal muscle biopsy which shows abnormal mitochondria, including crystalloid inclusions on electron microscopy. These patients form a distinct clinical group in which the risk of sudden cardiac death is much less than it is in the Kearns-Sayre syndrome.
\end{abstract}

RÉSUMÉ: Nous présentons une revue clinique, électrophysiologique et pathologique de 14 patients souffrant de myopathie oculo-squelettique avec mitochondries anormales. Ces patients se présentent avec ophtalmoplégie et une faiblesse légère des muscles squelettiques. L'évolution de la maladie est lentement progressive. L'électromyographie montre des modifications myopathiques. Les enzymes sériques sont normaux. Le diagnostic est confirmé par une biopsie du muscle qui démontre des mitochondries anormales incluant, au microscope électronique, des inclusions crystaloides. Ces patients constituent un groupe clinique distinct chez qui le risque d'un décès soudain d'origine cardiaque est de beaucoup inférieurà celui trouvé dans le syndrome de Kearns-Sayre.

Can. J. Neurol. Sci. 1984; 11:390-394

The Kearns-Sayre syndrome is a well recognized clinical entity comprised of progressive external ophthalmoplegia with onset before the age of 20 , atypical retinitis pigmentosa, and heart block (Kearns and Sayre, 1958). Some of the many clinical abnormalities added since the original description include elevated CSF protein, short stature, cerebellar dysfunction and deafness (Berenberg et al., 1977; Karpati et al., 1973; Hudgson et al., 1972; Schneck et al., 1973). Prognosis in the KearnsSayre syndrome depends on the degree of cardiac conduction block, its recognition, and prompt treatment. Increasing recognition has been given to a specific picture in adults which includes progressive external ophthalmoplegia, minimal skeletal muscle weakness, and abnormal mitochondria (Kamieniecka, 1976; Kamieniecka and Schmalbruch, 1978; Kamieniecka and Schmalbruch, 1980; Morgan-Hughes and Mair, 1973; Olson et al., 1972; Tamura et al., 1974). These patients are considered a subgroup of the Kearns-Sayre syndrome. However, it is unclear as to whether this specific group of adult patients as described has the same risk of cardiac conduction abnormality.

We wish to report here our experience over the last 19 years with 14 patients in the adult group.

\section{Patients and Methods}

We have seen 14 adults with progressive external ophthalmoplegia, skeletal muscle weakness, and abnormal mitochondria ranging in age at last assessment from 30 to 75 years, the average age being 53 .

All patients had electromyographic examination of muscles using the DISA 1500 system and DISA concentric needle electrodes. Inspection of single motor units during weak voluntary activation was done, and a subjective estimate of the severity of abnormality made.

Every patient had a muscle biopsy: 11 deltoid, 1 biceps and 2 tibialis anterior. All biopsies were studied by light microscopy; on paraffin sections Haematoxylin and Eosin, periodic acid Schiff and Gomori connective tissue stains were used, while on frozen section preparations the modified Gomori trichrome stain and additional reactions for myofibrillar ATPase preincubated at $\mathrm{pH} 9.4$ and 4.3 , nicotinamide adenine dinucleotide tetrazolium reductase (NADH-TR), succinic dehydrogenase (SDH), and phosphorylase were carried out. Epoxy resin processed tissue was studied by electron microscopy. 


\section{RESULTS}

The clinical data and pertinent laboratory findings for all 14 patients are summarized in the table.

\section{Clinical Features}

Thirteen patients presented with an insidious, slowly advancing ocular disturbance consisting of ptosis and impaired eye movements. Age of onset varied from 1 to 40 years. Nine patients noticed an ocular problem some time before age 20 . Three patients came to our attention when seen by ophthalmologists for surgical repair of intractible ptosis. Two patients presented with swallowing difficulties. Eight patients were referred for neurological assessment of limb weakness and ophthalmoplegia. Only one patient presented with somatic weakness without ocular impairment. The duration of symptoms varied from 5 to 58 years with an average of 32.2 years. None of the patients were of French Canadian origin.

On examination 13 patients had ptosis which was severe in 12. Twelve had impaired ocular movements, and 13 had some facial weakness greater in the orbicularis oculi group than in the lower face. Three patients had bulbar impairment, thirteen had neck flexor weakness, and two had truncal weakness. All of the 14 patients had upper limb involvement - proximal and distal in 4, proximal only in 9, and distal only in 1 . Ten patients had lower limb weakness - proximal and distal in one, proximal only in eight, and distal only in one. Weakness was disabling in 1 patient.

None of the patients had symptomatic cardiac disease. Only two had abnormal electrocardiograms, both with left anterior hemiblock. One of these patients was 30 years old, and had short stature, and deafness. The other was 50 years old and had no other clinical abnormalities. One 67 year old woman had bilateral sensorineural deafness. The remaining eleven patients were free of associated features. In particular, none exhibited retinitis pigmentosa. Family history for similar eye and muscle disorders was negative in 12 patients. Two did have cousins with ptosis. The cerebrospinal fluid was not examined.

\section{Electrophysiologic Findings}

Myopathic changes consisting of increased numbers of shortduration, polyphasic, low amplitude motor units were seen in the proximal muscles of 13 patients. A large number of myopathic motor units occurred diffusely in 8 patients $(2+)$. Patchy changes were seen in $5(1+)$. One patient had a normal examination (0).

\section{Pathologic Findings}

Mild variation in fibre size with scattered atrophic fibres and occasional internal nuclei were seen in all cases. Histographic analysis was performed in 13 of the 14 cases and in only 6 was there considered to be a significant degree of fibre size variation. However, this was not consistent and appeared to be unrelated to the duration of the patients' illness. Three patients showed hypertrophy of type II fibres and in two, there was type I fibre hypertrophy.

Biopsies from all the patients exhibited type I fibre predominance, although the degree was quite variable with type I/II ratios ranging from 1.6 to 18.1 . In addition, varying numbers of fibres contained aggregates of mitochondria of variable size, usually seen in a subsarcolemmal position and appearing as dark masses with the NADH-TR or SDH reactions Fig. 1 (a, b \& c), or as irregular red deposits in the modified Gomori trichrome. Invariably these were in type I fibres and the number of fibres involved was variable; $8-43 \%$ of total fibres, or $14-45 \%$ of type I fibres (table).

At the ultrastructural level, these aggregates were composed of mitochondria of varying sizes and shapes exhibiting altered structure with multiplicity of cristae, crystalloid inclusions and dense amorphous matricies Fig. 2 (a, b, c). Other more nonspecific changes such as ' $Z$ ' line streaming, autophagic vacuoles and tubular aggregates were present on occasion.

\section{Discussion}

This series of adult patients with oculoskeletal myopathy and abnormal muscle mitochondrial aggregates forms a clinical entity distinct from the Kearns-Sayre syndrome. Olson et al. (1972), Kamieniecka (1976), and Morgan-Hughes and Mair (1973) have reported similar series with adult patients having progressive external ophthalmoplegia and variable skeletal muscle weakness. The course and prognosis in these published cases was not clear, and the number of patients was small.

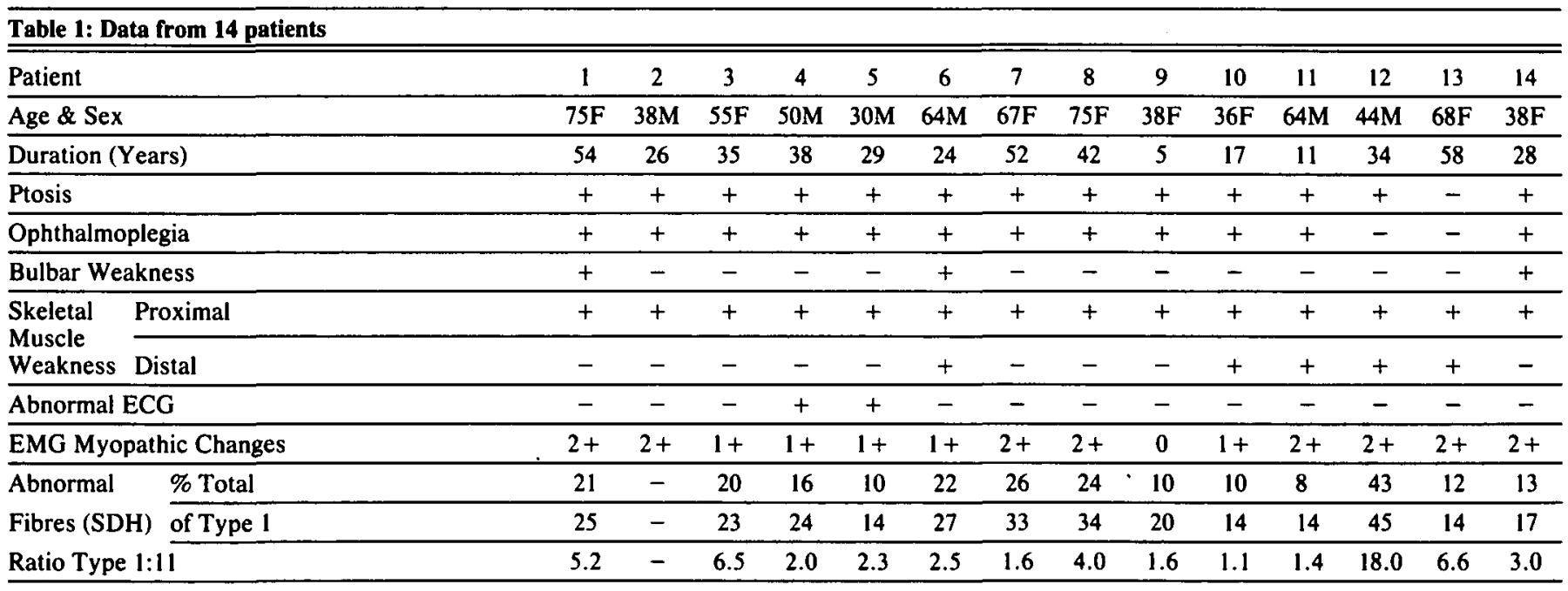



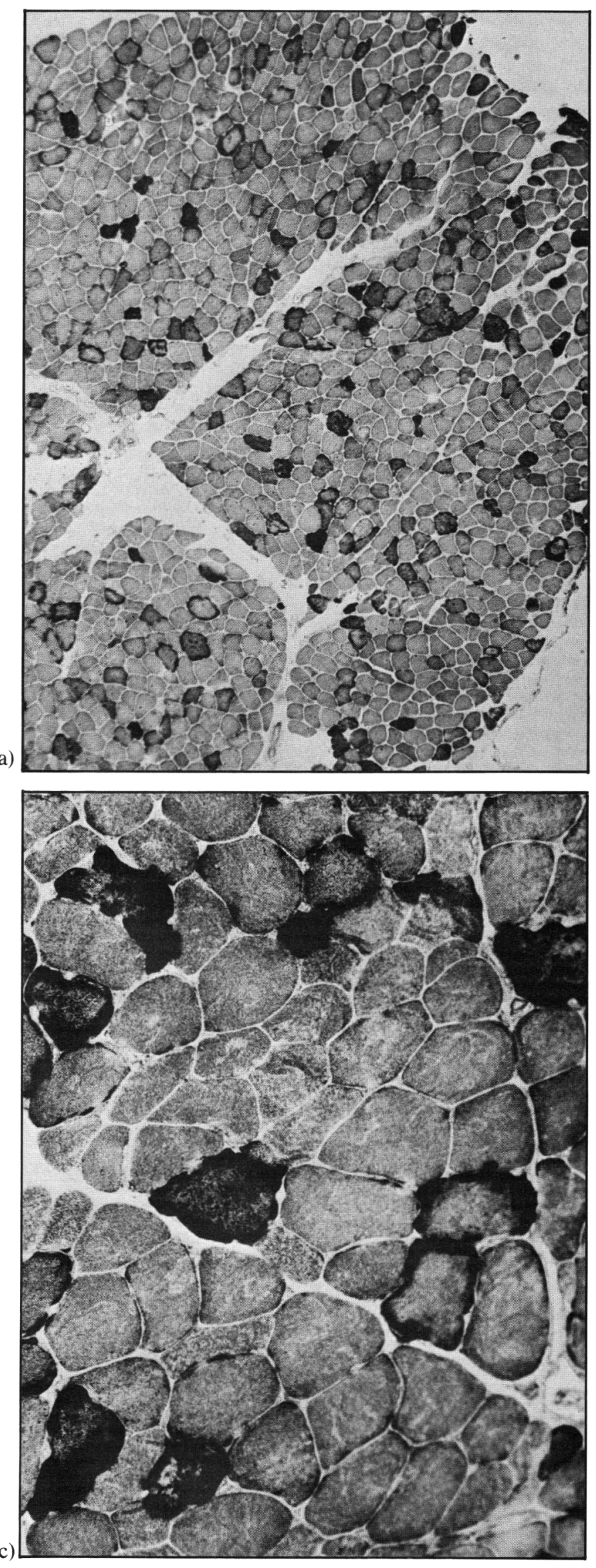

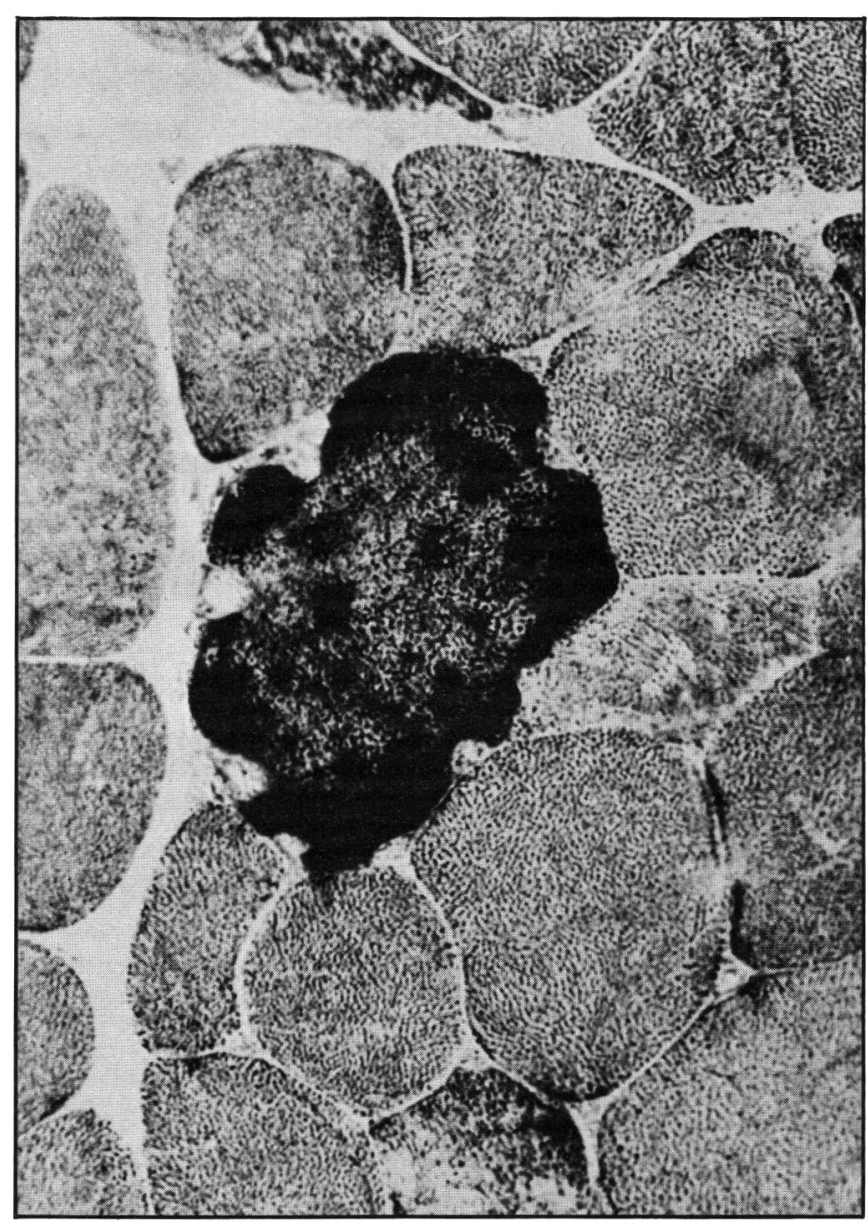

b)

Figure $1-a)$ Abnormal fibres containing subsarcolemmal deposits are readily seen though not always in such abundance. Patient No. I2 NADH-TR Mag. $x 28$. b) \& c) Greater magnification details the structural abnormality, the clear peripheral indentations due to nuclei. b) Patient No. 12 NADH-TR Mag. x 280. c) Patient No. 7 SDH Mag. x 120. 

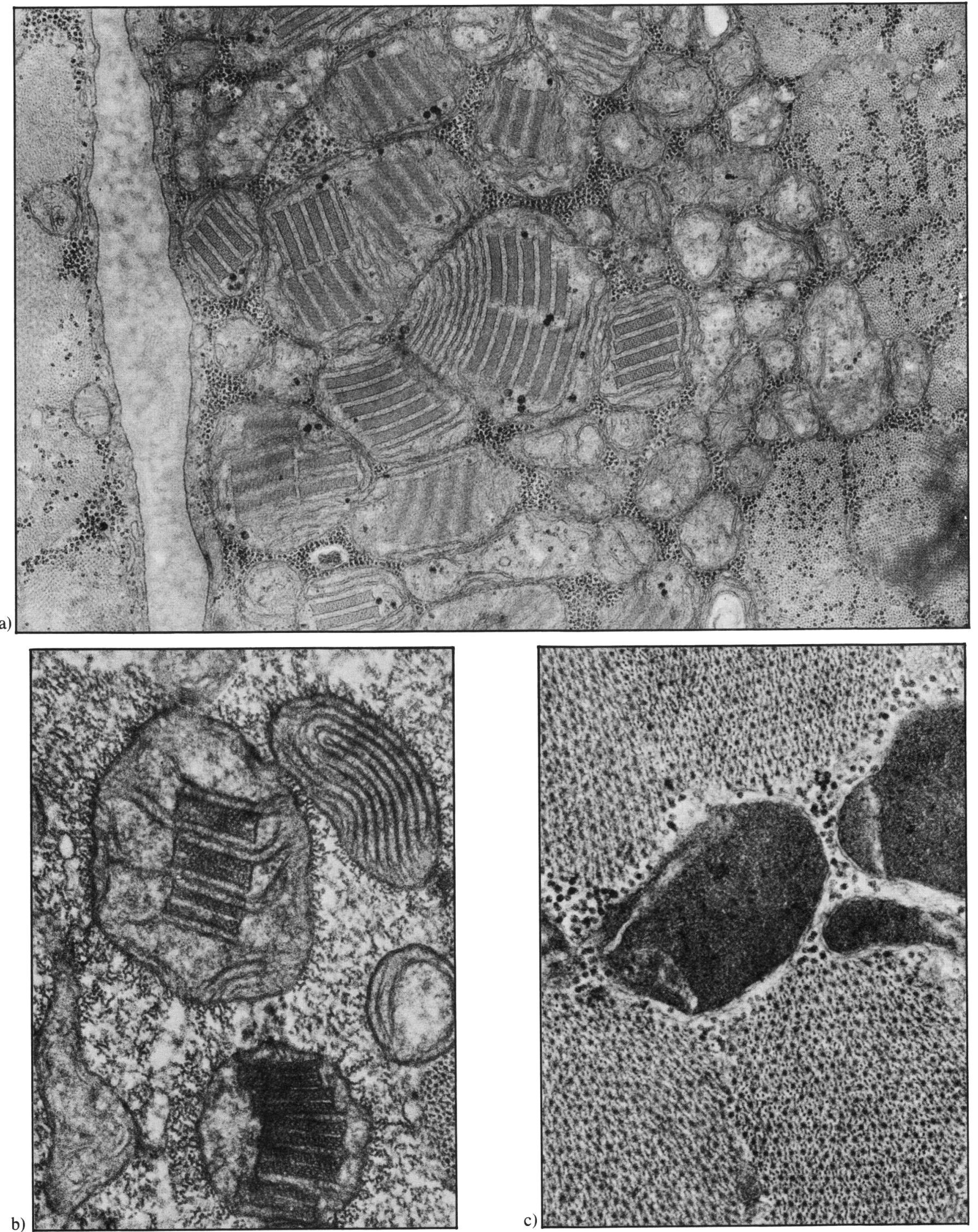

Figure 2 - a) A subsarcolemmal aggregate shows many enlarged abnormal mitochondria. Mag. $x 35,200$. b) Mitochondria exhibiting abnormal cristae and crystalloid inclusions. Mag. $x 75,300$. c) Mitochondria exhibiting dense amorphous matricies. Mag. $x 75,300$. 
As shown by our patients, the disease in adults is insidious and slowly progressive. Age of onset is highly variable, and frequently uncertain due to the subtle early manifestations. One half of our patients were over 50 years of age, and had been afflicted for periods ranging from 11 to 58 years. Only 1 patient had significant disability. Thus, the disease follows a benign course. All patients had proximal skeletal muscle weakness, but only 5 of 14 had distal involvement.

Three of our patients had dysphagia and dysarthria, raising the possibility of oculopharyngeal muscular dystrophy (Victor et al., 1962). We believe that these three cases are distinct from oculopharyngeal dystrophy since none had a positive family history of myopathy and none were of French Canadian origin. In addition, ragged red fibres are seen only rarely in oculopharyngeal muscular dystrophy (Karpati, 1979).

Our results do not show a strong correlation between the degree of clinical involvement and severity of electrical or pathological change. Quantitative electromyographic examination is essential in future studies if better correlations between clinical, electrical, and pathological fibre involvement are to be discovered.

Cardiac conduction defects are infrequent and asymptomatic in this group. In contrast Berenberg (1977)has shown a progressive block of cardiac conduction in patients with the full KearnsSayre syndrome, and sudden death in these patients may presumably result from complete heart block. It is essential, therefore, to carefully monitor the cardiac status of KearnsSayre patients. Although only two of our patients had abnormal ECG's, and none had symptomatic cardiac disease, we suggest that their cardiac conduction be assessed carefully. However, it appears that the older the patient, the less likely that there will be abnormal cardiac conduction.

In conclusion, the patients we have reviewed form a clinical disorder distinct from the classical Kearns-Sayre syndrome. The features include progressive external ophthalmoplegia, mild skeletal muscle weakness and a slowly progressive course. The diagnosis is confirmed by (1) normal muscle enzymes (2) myopthic changes on electromyographic examination and, (3) abnormal skeletal muscle biopsy with mitochondrial changes (increased numbers, abnormal sizes and shapes, and crystalloid inclusions). In contrast to the Kearns-Sayre syndrome, sudden death due to cardiac involvement is unlikely, and the ultimate prognosis in these patients is benign.

\section{REFERENCES}

Berenberg RA, Pellock JM, DiMauro S, Rowland LP (1977) Lumping or splitting? "Ophthalmoplegia-Plus" or Kearns-Sayre Syndrome? Ann. Neurol., 1: 37-54.

Hudgson P, Bradley WG, Kenkison J (1972) Familial "mitochonrial" myopathy, a myopathy associated with disordered oxidative metabolism in muscle fibres. Part 1. Clinical, Electrophysiological and Pathological Findings. J. Neurol. Sci., 16: 343-370.

Kamieniecka Z (1976) Myopathies with abnormal mitochondria. Acta Neurol. Scand. 55: 57-75.

Kamieniecka Z, Schmalbruch H (1976) Myopathies with abnormal mitochondria; A clinicopathologic classification. Muscle and Nerve 1: 413-415.

Kamieniecka Z, Schmalbruch H (1980) Neuromuscular disorders with abnormal muscle mitochondria. Int. Rev. of Cytol., 65: 321-357.

Karpati G (1979) Handbook Clinical Neurology. Ed. P.J. Vinken \& G.W. Bruyn. Vol. 40, Diseases of Muscle pt. 1, Chapter 1.

Karpati G, Carpenter S, Larbrisseau A, Lafontaine R (1973) The KearnsShy Syndrome, A multisystem disease with mitochondrial abnormality demonstrated in skeletal muscle and skin. J. Neurol. Sci. 19: 133-151.

Kearns TP, Sayre GP (1958) Retinitis pigmentosa, external ophthalmoplegia, and complete heart block. Arch. Ophthal., 60: 280-289.

Morgan-Hughes JA, Mair WGP (1973) Atypical muscle mitochondria in oculoskeletal myopathy. Brain, 96: 215-224.

Olson W, Engel, King W, Walsh GO, Einaugler R (1972) Oculocraniosomatic neuromuscular disease with "ragged-red" fibres. Arch. Neurol. 26: 193-211.

Schneck L, Adachi M, Briet P, Wolintz A, Volk BW (1973) Ophthalmoplegia plus with morphological and chemical studies of cerebellar and muscle tissue. J. Neurol. Sci., 19: 37-44.

Tamura K, Santa T, Kuroiwa Y (1974) Familial oculocranioskeletal neuromuscular disease with abnormal muscle mitochondria. Brain, 97: 665-672.

Victor M, Hayes R, Adams RD (1962) Oculopharyngeal muscular dystrophy. A familial disease of late life characterised by dysphagia and progressive ptosis of eyelids. New Eng. J. Med., 267: 1267. 